\title{
Mobile addiction and its relationship with quality of life in medical students
}

\author{
Mohammadreza Miri ${ }^{\mathrm{a}}$, Amir Tiyuri ${ }^{\mathrm{b}}$, Maryam Bahlgerdi ${ }^{\mathrm{a}}$, Maryam Miri ${ }^{\mathrm{a}}$, Farzaneh Miri ${ }^{\mathrm{a}}$, \\ Hamid Salehiniya ${ }^{\mathrm{a}, *}$ \\ ${ }^{a}$ Social Determinants of Health Research Center, Birjand University of Medical Sciences, Birjand, Iran \\ ${ }^{\mathrm{b}}$ Student Research Committee, Iran University of Medical Sciences, Tehran, Iran
}

A R T I C L E I N F O

\section{Keywords:}

Quality of life

Cell phone

Addictive behavior

Medical students

Iran

\begin{abstract}
A B S T R A C T
Background: Quality of life is one of the most important health-related outcomes that can be affected by mobile phone addiction. This study was conducted to determine the prevalence of mobile phone addiction and its relationship with quality of life in students of Birjand University of Medical Sciences (BUMS).

Methods: This cross-sectional study was conducted on 360 students in BUMS in 2018. The sample was randomly selected from each faculty using proportional stratified sampling. To collect data, a questionnaire containing the demographic variables, the PMPAS questionnaire for mobile addiction and SF-12 for quality of life were used. Data were analyzed by independent $t$-test and Pearson correlation coefficient in SPSS (V.18).

Results: The mean age of the students was $25.1 \pm 6.3$ years that $75.5 \%$ were female. In terms of marital status, $60.6 \%$ were single. Nearly $75 \%$ of students were with moderate or severe mobile phone addiction. The score of mobile phone addiction was higher in single and younger students $(\mathrm{p}<0.001)$. The mean score of quality of life for the students in two aspects of the physical and mental component were 50.81 and 42.86 respectively. Based on the results, there was a significant inverse relationship between scores of mental function and mobile phone addiction $(r=-0.35, \mathrm{p}<0.001)$, this relation was not significant for physical function $(\mathrm{r}=-0.60, \mathrm{p}=0.25)$. Conclusions: According to the results, the prevalence of mobile phone addiction among students was high and mobile phone addiction has a negative effect on the quality of life of students, which has a negative effect on psychological performance.
\end{abstract}

\section{Introduction}

One of the most popular communication tools which is available for most of the people is the mobile phone. ${ }^{1,2}$ The portability, permanent access and features of mobile phones, especially new smartphones, have resulted in the widespread use of mobile phones, and the use of them is rising in all countries. ${ }^{3,4}$ The development of communication and technology, although in various fields, such as accelerating work and reducing distances, is an opportunity but can simultaneously be regarded as a threat and affect various aspects of human health. ${ }^{5,6}$ As an illustration, based on the results of various studies of electromagnetic waves released, it can cause problems in human health..$^{7-9}$ Meanwhile, there is no enough attention to the psychological and social effects of long and excessive use of this communication device. Excessive use of mobile phones is a situation in which there is a lot of use of mobile phones and mental engagement. ${ }^{3}$ Kamibeppu and Sugiura ${ }^{10}$ and Billieux et al. ${ }^{11}$ claim that mobile addiction capacity should not be neglected. In addition to texting and voice communication, today's smartphones provide many services to their users, such as internet connectivity, social networking, and entertainment. ${ }^{12}$ Having these features, mobile availability and ease of use it compared to personal computers or laptops, will allow users to spend a lot of time on it, and this excessive use, as well as subsequent addiction to it, can affect the quality of life. ${ }^{13}$ Quality of life is one of the most important healthrelated outcomes that World Health Organization recognizes as a person's perception of his position in life in the context of the cultural and value systems in which person lives and determined in relation to his goals, expectations, standards, and concerns. Quality of Life is a broad concept that is influenced by a complex set of physical, psychological, personal beliefs, social and environmental relationships. ${ }^{14}$ In recent years, the subject of computer and internet addiction has been widely debated, and researches have shown that there is a close relation between overuse of computer and the internet and various physical and mental disorders. ${ }^{15-17}$ Excessive use of mobile phones, especially with the advent of new smartphones, the issue of mobile phone addiction and its consequences have become very important. In relation with the

\footnotetext{
* Corresponding author. School of Public Health, Birjand University of Medical Sciences, Birjand, Iran.

E-mail addresses: alesaleh70@yahoo.com, hamid.salehi@bums.ac.ir (H. Salehiniya).
} 
excessive use of mobile phones, the results of studies have shown that the physical and psychological effects of overuse of mobile phones include symptoms such as headache, warmth in the ear, memory weakness, fatigue, anxiety, and depression. ${ }^{3,5,18,19}$ Nevertheless, the need for studies to examine the impact of excessive mobile phone use on quality of life as an important outcome is felt. Therefore, considering the importance of mobile phone addiction and quality of life especially in students and the lack of a similar study on medical students at Birjand University of Medical Sciences (BUMS), the present study was conducted to determine the prevalence of mobile phone addiction and its relationship with quality of life in students of BUMS in 2018.

\section{Methods}

\subsection{Sampling method \& sample size calculation}

This cross-sectional study was conducted on 360 students in BUMS in 2018. The population of this study was all students of BUMS in 2018 and that from them; random sampling was done by proportional stratified sampling and according to the faculty. To estimate the sample size, the formula for calculating the sample size for correlation between two quantitative variables was used. For this purpose, the mean-to-low correlation coefficient was used to estimate sample size with $95 \%$ power and an alpha level of 5\% and the calculated sample size was 360 . The required sample was selected randomly and independently from the list of students in each faculty by coordination of university education. After selecting the subject, the description of the research was provided, if the participant agreed, entered the project.

\subsection{Data collection techniques}

To collect data in this study, in addition to the questions related to demographic characteristics (including age, sex, educational level, faculty, marital status, and type of residence), PMPAS questionnaire for mobile addiction and SF-12 for quality of life were used:

1-The Persian version of the Mobile Phone Addiction Scale (PMPAS) questionnaire was used to investigate the mobile phone addiction. The questionnaire contains 15 questions and 3 subscales of inability to control craving (8 questions), feeling anxious and lost (5 questions) and mood improvement ( 2 questions), that questions in the 5-point scale with never, rarely, sometimes, often and always, are scored from 1 to 5 , and each person will have a score of between 15 and 75. Scores of less than 30 regarded as ordinary users, 30 to 60 mild addictions, and more than 60 were considered as a severe addiction to mobile phone. The validity and reliability of this questionnaire were confirmed in the study of Mazaheri and Karbasi on students of Isfahan University of Medical Sciences, after translating and applying expert opinions, for the whole questionnaire with Cronbach's alpha 0.86 , for the first sub-scale with Cronbach's alpha, 0.84 , for the second sub-scale With Cronbach's alpha, 0.81 and for the third sub-scale with Cronbach's alpha of $0.72 .^{20}$

2-The short form 12 questionnaire (SF-12) was used to assess the quality of life, which is a shorter form of the SF-36 questionnaire. This questionnaire has two general components of physical and mental function with 12 questions and 8 scales of physical functioning (2 questions), bodily pain (1 questions), role limitations due to physical problems (2 questions), general health (1 question) vitality (1 question), social functioning (1 question), role limitations due to emotional problems (2 questions) and perceived mental health (2 questions). After doing the necessary measures, the score for each area was obtained separately, and each person's score for the two components of the Physical Component Summary (PCS) and the Mental Component Summary (MCS) was calculated. Validity and reliability of this questionnaire were approved and standardized by Montazeri et al. for the Iranian population with Cronbach's alpha of $0.72 .{ }^{21}$

\subsection{Ethical considerations}

This study was approved by Birjand University of Medical Sciences at the number of 1126 . The subjects were informed consciously and after the consent, the questionnaires were collected without the name and profile of the students.

\subsection{Data analyses}

After collecting data, they were entered into SPSS (PASW Statistics for Windows, Version 18.0, Chicago: SPSS Inc., USA) and data were analyzed by independent $t$-test and Pearson's correlation coefficient at $\alpha=0.05$.

\section{Results}

In the final, 353 questionnaires entered the analysis, the mean age of the students was 25.07 with a standard deviation of 6.29 years. In terms of marital status, $214(60.6 \%)$ were single and the rest were married. $75.5 \%$ of the subjects were female and the rest (24.5\%) were male, $60.2 \%$ were indigenous and the rest were non-native. According to the results, $25.3 \%$ of the subjects had a low dependency to cell phone and nearly $75 \%$ had moderate to severe addiction to use of it $(72.6 \%$ moderate dependence and $2.4 \%$ severe dependence), according to this, there is a high dependency to mobile phone among students.

The mean score (standard deviation) of the students in terms of mood improvement was 6.1 (2.1), which is higher than the average questionnaire score. For feeling anxious and lost, the mean score was 14.33 (5.0). These results indicate that the scores of the subjects are higher in the sense of anxiety. In the case of inability to control craving, the mean score was 17.5 (5.8) that was lower than the average questionnaire score; however, the score is high and demonstrate the inability of individuals to control the tendency.

In Table 1 comparison of mean of the mobile phone addiction score according to various factors indicates that there is no significant difference between the two sexes in terms of the average score of addiction to the phone $(\mathrm{p}=0.34)$, mean score of mobile phone addiction was significantly higher in singles than married students ( $p<0.001$ ), this difference was not seen between native and non-native groups $(\mathrm{p}=0.50)$.

Also, between age and score of addiction to the mobile phone, the correlation coefficient was -0.27 and the significance level was 0.001 . Accordingly, there is an inverse and significant correlation between these two variables, and as the age increases, the score of addiction to the mobile phone decreases. The measurements were made to calculate the quality of life score and the scores were defined as zero to one hundred (zero is the worst condition of quality of life), accordingly, the mean score of quality of life of the subjects in the two components of physical function and mental function was 50.81 (8.8) and 42.86 (13.5) respectively.

A correlation coefficient was used to examine the relationship between quality of life score and score of mobile phone addiction. Table 2 shows the result of the correlation test between quality of life components and mobile phone addiction, as we can see, there is a significant

Table 1

Comparison of the mean of mobile phone addiction according to the demographic variables in students.

\begin{tabular}{lllc}
\hline Variable & Sub variable & Mean (SD) & P \\
\hline Sex & Female & $38.44(11.07)$ & 0.34 \\
\multirow{2}{*}{ Type of residence } & Male & $37.09(10.58)$ & \\
& Native & $37.92(11.35)$ & 0.50 \\
Marital Status & Non-native & $38.76(10.33)$ & \\
& Single & $39.90(10.77)$ & $<0.001$ \\
& Married & $35.09(10.79)$ & \\
\hline
\end{tabular}


Table 2

Correlation between scores of quality of life and mobile phone addiction in students.

\begin{tabular}{lll}
\hline Variable & Correlation coefficient & $\mathrm{P}$ \\
\hline Physical Component Summary & -0.60 & 0.25 \\
Mental Component Summary & -0.35 & $<0.001$ \\
\hline
\end{tabular}

and inverse relationship between mental component and mobile phone addiction ( $\mathrm{p}<0.001)$, and with the increase in the score of mobile phone addiction, the quality of life of individuals decreases; this relationship was not significant for physical component $(\mathrm{p}=0.25)$.

\section{Discussion}

The aim of the present study was to determine the prevalence of mobile phone addiction and its relationship with quality of life in students of BUMS in 2018.

According to the results of the present study, the prevalence of mobile phone addiction was high among the students, and with the increase in the score of mobile addiction, the quality of life of students, especially in the component of mental function, worsens.

In this study, nearly $75 \%$ of students have moderate or severe mobile phone addiction that was at high levels. A study in Zahedan shows the high prevalence of addiction to the internet. ${ }^{22}$ Other studies also indicate a high degree of dependence on mobile phones and virtual networks and the internet, ${ }^{23}$ studies have revealed that the prevalence of mobile phone addiction among students is an important part of people's lives that can put people at serious risk, which is higher in adolescents and young adults. ${ }^{24}$

Nowadays, mobile phone, along with voice and text communication, provides plenty of services such as connecting to the internet, communicating with social networks and entertainment for its users. ${ }^{12}$ This growth in technology can affect all aspects of life. ${ }^{5}$ The growth of communication and technology, although in various areas, such as speeding up work and reducing distances, is an opportunity, at the same time it is an important threat to human health..$^{7-9}$ However, due to the psychological and social effects of long and excessive use of this means of communication, attention has not been paid enough. Excessive use of mobile phones is a situation in which cell phone use is high and there is a lot of mental employment. ${ }^{3}$

In the present study, there was no significant relationship between demographic variables and mobile phone addiction, except in terms of marital status and age. Accordingly, single and younger students have more mobile phone addiction, the results of this study are in line with other studies. ${ }^{23}$ The use of social and mobile networks is more common in single and young students because of personality and freedom characteristics and more time, ${ }^{25}$ hence, considering to programs for reducing using of mobile phone and alternative entertainments are useful for young and single students.

In the present study, there was an inverse relationship between the score of mobile phone addiction and quality of life, with the increasing dependence on mobile phones, the quality of life of individuals, especially in the mental function, become worse. Quality of life of students and other psychological aspects such as academic performance are heavily dependent on mobile phone addiction and the use of social networks. $^{23}$

Increasing the use of mobile phones can cause mental disturbances, stress, and anxiety in individuals, ${ }^{5,22}$ Hence, Internet addiction and Cyberspace can negatively affect student quality of life. ${ }^{22}$ According to studies, increased use of the internet and elevated tendency to Cyberspace is associated with mental disorders and quality of life in persons. ${ }^{26}$ In addition to the negative impact on quality of life, mobile phone and internet addiction, can affect grade point average negatively and cause academic failure. ${ }^{18,22}$
Limiting the use of mobile phones in individuals can be positively associated with effective improved performance in various aspects of life. ${ }^{27}$ Hence, interventional and educational programs to reduce the use of mobile phone and its applications to improve students' quality of life seem necessary. ${ }^{22}$

Limitations: The self-reporting questionnaire is one limitation because some students may not have enough attention to complete the questionnaire or have not responded accurately to questions. This study is a cross-sectional study, therefore, the inference of the cause and effect relationship is not possible.

\section{Conclusions}

In the present study, the prevalence of mobile phone addiction in students was high and excessive use of mobile phones has a negative impact on the quality of life of students. Since increasing the use of mobile phones can affect the quality of life and other aspects of student life, the implementation of educational and intervention programs to reduce the use of mobile phones among students seems necessary.

\section{Funding}

This study supported by Birjand University of Medical Sciences.Acknowledgments

This study was approved by the Deputy of Research and Technology of Birjand University of Medical Sciences at number 1126. Therefore, the authors of the study appreciate the deputy of Research and Technology due to the material and spiritual support and the cooperation of all students who completed the questionnaires.

\section{Conflicts of interest}

None.

\section{Appendix A. Supplementary data}

Supplementary data to this article can be found online at https:// doi.org/10.1016/j.cegh.2019.08.004.

\section{References}

1. World Health Organization. Public health implications of excessive use of the internet, computers, smartphones and similar electronic devices: meeting report. Main Meeting Hall, Foundation for Promotion of Cancer Research, National Cancer Research Centre, Tokyo, Japan, 27-29 August 2014. World Health Organization; 2015.

2. Al-Hadidi F, Bsisu I, AlRyalat SA, et al. Association between mobile phone use and neck pain in university students: a cross-sectional study using numeric rating scale for evaluation of neck pain. PLoS One. 2019;14 e0217231-e0217231.

3. Jenaro C, Flores N, Gómez-Vela M, González-Gil F, Caballo C. Problematic internet and cell-phone use: psychological, behavioral, and health correlates. Addict Res Theor. 2007;15:309-320.

4. Alexiou GA, Sioka C. Mobile phone use and risk for intracranial tumors. J Negat Results Biomed. 2015;14:23.

5. Yioultsis TV, Kosmanis TI, Kosmidou EP, et al. A comparative study of the biological effects of various mobile phone and wireless LAN antennas. IEEE Trans Magn. 2002;38:777-780.

6. Chiu CT, Chang YH, Chen CC, Ko MC, Li CY. Mobile phone use and health symptoms in children. J Formos Med Assoc. 2015;114:598-604.

7. Kundi M, Mild K, Hardell L, Mattsson MO. Mobile telephones and cancer-a review of epidemiological evidence. J Toxicol Environ Health B Crit Rev. 2004;7:351-384.

8. Lu Y, Huang Y. Biological effects of mobile phone radiation. 2012 International Conference on Microwave and Millimeter Wave Technology (ICMMT). 2012; 2012:1-4.

9. Repacholi MH. Health risks from the use of mobile phones. Toxicol Lett. 2001;120:323-331.

10. Kamibeppu K, Sugiura H. Impact of the mobile phone on junior high-school students' friendships in the Tokyo metropolitan area. Cyberpsychol Behav. 2005;8:121-130.

11. Billieux J, Van der Linden M, d'Acremont M, Ceschi G, Zermatten A. Does impulsivity relate to perceived dependence on and actual use of the mobile phone? Appl Cognit Psychol. 2007;21:527-537.

12. Khazaie T, Saadatjoo A, Dormohamadi S, Soleimani M, Toosinia M, Mullah Hassan Zadeh F. Prevalence of mobile dependency and adolescence aggression. $J$ Birjand Univ Med Sci. 2013;19:430-438.

13. Lepp A, Barkley JE, Karpinski AC. The relationship between cell phone use, academic 
performance, anxiety, and Satisfaction with Life in college students. Comput Hum Behav. 2014;31:343-350.

14. World Health Organization. WHOQOL: measuring quality of life. Health Stat Inf Syst. 2014https://www.who.int/healthinfo/survey/whoqol-qualityoflife/en/.

15. Fatehi F, Monajemi A, Sadeghi A, Mojtahedzadeh R, Mirzazadeh A. Quality of life in medical students with internet addiction. Acta Med Iran. 2016;54:662-666.

16. Potembska E, Pawlowska B, Szymanska J. Psychopathological symptoms in individuals at risk of Internet addiction in the context of selected demographic factors. Ann Agric Environ Med. 2019;26:33-38.

17. Li G, Hou G, Yang D, Jian H, Wang W. Relationship between anxiety, depression, sex, obesity, and internet addiction in Chinese adolescents: a short-term longitudinal study. Addict Behav. 2019;90:421-427.

18. Hocking B, Westerman R. Neurological effects of radiofrequency radiation. Occup Med (Lond). 2003;53:123-127.

19. Oftedal G, Wilen J, Sandstrom M, Mild KH. Symptoms experienced in connection with mobile phone use. Occup Med (Lond). 2000;50:237-245.

20. Mazaheri MA, Karbasi M. Validity and reliability of the Persian version of mobile phone addiction scale. J Res Med Sci. 2014;19:139-144.

21. Montazeri A, Vahdaninia M, Mousavi SJ, Omidvari S. The Iranian version of 12-item Short Form Health Survey (SF-12): factor structure, internal consistency and construct validity. BMC Public Health. 2009;9:341.

22. Ebrahimi S, Khammarnia M, Porvazn N, et al. The prevalence of internet addiction and its relationship with quality of sleep and quality of life among students of zahedan university of medical Sciences. J Sch Public Health Inst Public Health Res. 2018;16:126-137.

23. Sadoughi M. The relationship between problematic mobile usage and academic performance among students: the mediating role of sleep quality. Educ Strategy Med Sci. 2017;10:123-132.

24. Mousavomoghadam SRA, Nouri T, Khodadadi T, Ahmadi A, Ghiasi G. Association of internet addiction and self-control with mental health among students of the university of applied Sciences and technology, ilam city, Iran. J Sch Public Health Inst Public Health Res. 2017;15:1-8.

25. Mousavi SK, Shafigh Y. Addiction to mobile at tehran's youth: a sociological study. Ir J Sociol. 2017;17:139-164.

26. Malekahmadi H, Jafariyan A. Pathology of internet addiction. J Hist Sociol 2012:3:93-116.

27. Sahbaei F, Shokri S, Daemi M, Pourzadi M. Mobile phone use patterns amongst university students: its correlates and relationship to psychological health. J Med Counc IRI. 2016;34:233-240. 